\title{
A Comparative Study of Loss Allocation before and after Loss Reduction by RED Concept in Deregulated Power System
}

\author{
P.K.Hota ${ }^{1 *}$, A.P.Naik ${ }^{2}$ \\ ${ }^{1}$ Department of Electrical Engineering, Veer Surendra Sai University of Technology (VSSUT), Burla, India \\ ${ }^{1}$ p_hota@rediffmail.com \\ ${ }^{2}$ Department of Electrical Engineering, Bhadrak Institute of Engineering and Technology, Bhadrak, India \\ 2atulya_naik@rediffmail.com
}

\begin{abstract}
In the deregulated power system environment the transmission loss plays an important role. Both its allocation and reduction impact a lot on economic consideration. Due to the nonlinearity nature, the allocation of transmission loss among different utilities creates a challenging task. This paper proposes a new formula for transmission loss allocation based on actual usage of line. It splits a common transmission line into as many sub-lines corresponding to the number of loads attached to it. It divides the total loss of the common line among the sub-lines in proportion to their individual power sharing. The net loss allocated to a particular load is the combination of individual loss occurring in different sub-lines which are concerned to the said load under the whole system. To apply this formula, the load flow solution of the system network along with the power flow tracing of lossy lines are computed. This paper uses Newton-Raphson based iterative technique to obtain the load flow solutions and proportional sharing method for power flow tracing. The proposed formula is applied to a six-bus case to prove its viability and subsequently used to find the loss allocation in IEEE-14 and IEEE-30 bus systems. Relative Electrical Distance (RED) concept which is based on topology of the system and readjustment of generations has been utilized to reduce the loss in both the systems. The amounts of loss reduction in both the cases are found to be significant. Again the loss allocations of the two systems are worked out using the proposed formula and finally comparison of loss allocations before and after the loss reduction have been presented.
\end{abstract}

Keywords: Line flow, Power flow tracing, Lossy lines, Relative Electrical Distance (RED), Loss allocation

\section{INTRODUCTION}

Transmission loss arises when the electric power flows through the transmission line to meet the customer's load demand. In the pre-deregulated system, these losses were overlooked, as they did not pose any major problem in quality or operational supply of power. However, in the deregulated era transmission loss impacts a lot in the economic aspects. Therefore, minimization of transmission loss is a paramount task. Reduction of loss is quantified as savings in generation cost. In deregulated market structure, financial sectors are imposing condition to ensure less transmission loss mechanism before giving any financial assistance to the power company. In a larger interconnected network, factors like voltage regulation, circulating current, phase balancing, power factor, etc. influence more losses into the system. Network reconfiguration and resizing, preventing leakage at insulators, providing automatic voltage booster, better management of distribution transformers, load balancing and its management, fixing capacitors, adoption of high voltage distribution system are some of the ways that can be undertaken for loss reduction. Oke, et al. presented [1] a mathematical model of losses by taking ohmic loss and corona loss. It suggests operating of system under flat voltage loading and keeping the space between the conductors as large as compared to their diameter. Under practical field, maintaining flat voltage loading is a difficult task. Some of the action plans are described by Ibrahim [2] for loss reduction. However, it does not specify any particular one for loss reduction. Bidding mechanism has been employed by $\mathrm{Yu}$, et al. [3] to reduce the loss. Rosa, et al. [4] inserted wind turbine generators into the power grid to reduce active and reactive losses. The place to connect wind turbine is decided by incremental transmission loss method. Though it sounds logical but intermittency of wind would affect the voltage profile of the system. The requirement of reduction in transmission loss persists in both regulated and deregulated power systems. However, in particular to deregulated power system, loss reduction along with its allocations among different utilities is very much needed. While deciding the tariffs under regulated system, losses were taken as an extra load and expenditure occurred due to the system loss were collected from all the utilities irrespective of losses they made. But in the deregulated system, the services of generation, transmission and distribution are unbundled and hence, fairer tariff has to be assigned to the individual services. To fix a fair tariff, it is essential and mandatory to know the individual's loss amount. Unfortunately, transmission loss is a nonlinear quantity involving cross terms. Allocating it in a larger network is a challenging task. Different methods have been developed and still research is going on to give it a viable conclusion. A comparison of different practical algorithms for transmission loss allocation is presented by Canejo, et al. [5]. The assignment of cross terms in 
power equation, particularly when the involved transactions greatly differ in size, has been analyzed and some methods like proportional allocation, quadratic allocation, geometric allocation and fast geometric allocation are proposed by Exposito, et al. [6]. Converting all power injections into real and imaginary currents to avoid nonlinear coupling between active and reactive power flows caused by losses have been presented by Canejo, et al. [7]. Radial equivalent network approach has been discussed by Canejo, et al. [8]. Bisnas, et al. [9] describes a methodology for aggregation of nodal generation loss factors into zonal loss factors by considering electrical proximity of nodes to the zonal centers. Loss allocation based on fuzzy memberships and supervised neural network have been presented by Choudhury, et al. [10]. Khan, et al.[11] have presented a combined methodology for transmission usage and loss allocation based on matrix formulation and game theory. Implications of India's new cost allocation method for Inter-State transmission have been analyzed by Beckman [12]. It describes the point of connection charging method. This works on flow-based transmission cost allocation framework. However, the successful implementation of this method largely depends on the robust open access regime and fair allocation of transmission loss. Loss allocation based on physical line flow of individual load gives more justification to the load. To know the individual line flow in a common transmission line, power flow tracing is required. A physical-flow-based approach in a multiple transaction system with a new concept of counter flow associated with the losses has been demonstrated by Gross, et al. [13]. Active and reactive power flow tracing between generators and loads based on proportional sharing principle are proposed in references [14-15]. Transmission cost allocations based on power flow tracing is presented by Khan, et al. [16]. Models have been proposed for effective reactive power flow tracing in references [17-18]. New power flow tracing methods based on directed circuit and extended incidence matrix have been presented in references [19] and [20], respectively. Calculation of transmission congestion price based on Bialek's power flow tracing principle has been presented by Chellam, et al. [21]. Here, both upstream and downstream algorithms were used to find out the power flow from generators to transmission lines and from generators to loads. Abdelkader [22] has proposed a new methodology that has been applied to transmission loss allocation based on power flow tracing. This presents more acceptable result over two widely applied methods such as proportional ratio (Prorata) and incremental transmission loss (ITL) in a six-bus system. However, this method gives some mismatch in justifying the total allocated loss equals with the total system loss particularly when applied to higher order bus systems.

As economic aspects in deregulated power system mainly depend on the active loss of a system, so this paper undertakes active power loss allocation of the system considering all the losses attributed to load sides. It uses proportional sharing method to trace out the active power in a common line, particular to the loss making line which is also called as lossy line. Based on physical flow of power, a new formula has been developed to allocate the loss for different loads. The main logic behind this formula is the segregation of each lossy line into as many sub-lines depending upon the numbers of loads attached to it, either directly or indirectly. Then total loss of the common line is divided among the loads with proportionate to their power receiving. This formula has been applied to the system in reference [22] and justified its viability. This is also used in the case study of IEEE-14 and IEEE-30 bus systems for loss allocations. Further, relative electrical distance (RED) concept [2326] which depicts the idea of getting power form the nearest generator by the load with minimum loss has been employed here to reduce the loss in IEEE-14 and IEEE-30 bus systems. Thereafter, the re-allocations of transmission loss have been worked out using the proposed formula and finally a comparative study has been presented.

\section{THE PROPOSED FORMULA}

The proposed formula allocates transmission losses to loads based on the actual physical usage of the line. It undertakes the idea which is well demonstrated and proved in reference [22] that when two or more currents share a conductor, they will have equal chances to occupy the conductor cross section. It means the effective area each conductor occupies will be proportional to its magnitude. This provides the insight to split a common line into as many as sub-lines corresponding to the numbers of loads that are attached to it either directly or indirectly. It means a load may directly receive the power from the receiving end of the common line or through other line but originated from the same receiving end of the said common line. Now the total loss of the common line may be allocated to different sub-lines with respect to the power flow through each of them.

\section{A. Mathematical Interpretation}

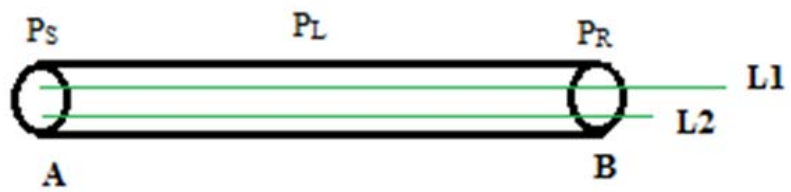

Fig.1. Illustration of splitting line and loss 
Fig. 1 shows the splitting of a common line $A B$ into the sub-lines of $L 1$ and $L 2$. It is assumed that two loads 1 and 2 are taking powers through line $A B . P_{S}$ is the sending end power at $A$ and $P_{R}$ is the receiving end power at B. $P_{L}$ is the total loss of the line $A B$. Now this loss is occurring in $A B$ due to the delivery of power, $P_{R}$ at $B$. This delivering of power is necessitated due to the demands of loads 1 and 2 . Hence the loss occurred in $A B$ must be borne by the loads 1 and 2 . Now to sort out the problem of total loss distributions or loss allocations between them, it is justified to allocate the loss in accordance with their individual power demand at the receiving end of line $A B$.

If $P_{D 1}$ and $P_{D 2}$ are the power demands of loads 1 and 2, then using proportional ratio principle;

Loss allocation to load $1, P_{L O S S 1}=\frac{P_{D 1}}{P_{R}} \times P_{L}$

and loss allocation to load $2, P_{L O S S 2}=\frac{P_{D 2}}{P_{R}} \times P_{L}$

\section{B. Application to Power Systems}

To apply this method to a larger power system network, firstly, the line flow of the system has to be found out and this can be done by using any programmed based numerical iterative technique. Secondly, by using any suitable power sharing method [15], the active line flows of individual loads are to be traced out in a common transmission lossy line. The active line flows in lossy lines caused by different loads of the system are to be arranged in a matrix form such as:

$\left[F_{\text {active }}\right]=\left[f_{i, j}\right]$

Where, $f_{i, j}$ is the active line flow caused by the load ' $i$ ' in lossy branch ' $j$ '.

Then, the active loss allocations for the different loads by using the proposed formula are computed as:

$\left[P_{\text {LOSS }}\right]_{i}=\left[F_{\text {active }}\right] *\left(\left[P_{L}\right] . /\left[P_{R}\right]\right)$

Where, $\left[P_{L}\right]$ and $\left[P_{R}\right]$ are the active line losses and receiving end active powers of lossy lines, respectively. Both are column matrices whose rows are equal to the number of lossy lines.

$\left[P_{\text {LOSS }}\right]_{i}$ is a column matrix of size $\left(L_{B} \times 1\right)$ and $L_{B}$ is the number of load buses of the system.

\section{APPLICATION OF PROPOSED FORMULA AND TEST RESULTS}

The proposed formula is applied elaborately to the six-bus test system adopted from reference [22]. The results are compared with the two most commonly used methods such as ITL, Pro rata and the earlier results [22]. Subsequently, the proposed formula is used to find out the loss allocations in IEEE-14 and IEEE-30 bus test systems.

\section{A. Case Study-I (Six-Bus Test System)}

A six-bus system having two voltage-controlled buses and three load buses is shown in Fig. 2. Bus 1 and 2 are two voltage controlled buses and Bus 3,5 and 6 are load buses. Bus 1 is taken as the slack bus. The bus data, line data and transformer data of the system have been adopted from reference [22].

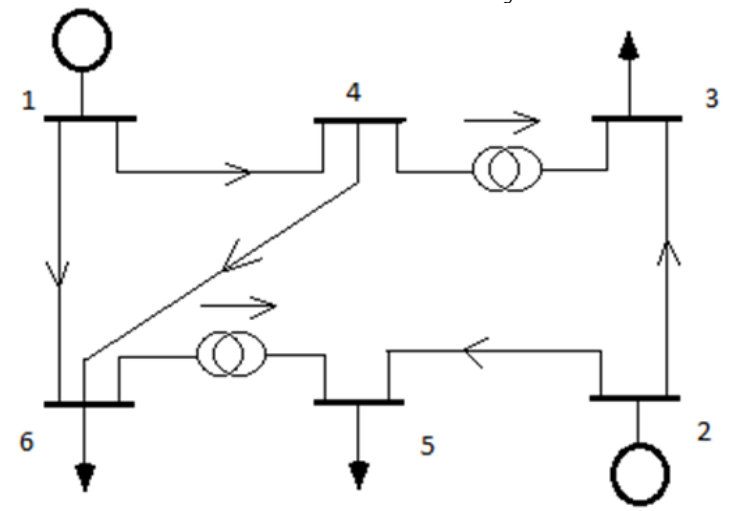

Table 1(a) Results of line flows and power loss

\begin{tabular}{|l|l|c|c|}
\hline \multicolumn{2}{|c|}{ Line } & $\begin{array}{c}\text { Receiving end active power } \\
\text { in } M W\end{array}$ & $\begin{array}{c}\text { Active loss in } \\
\text { MW }\end{array}$ \\
\hline From & To & $\mathrm{P}_{\mathrm{R}}$ & $\mathrm{P}_{\mathrm{L}}$ \\
\hline 1 & 4 & 48.728 & 2.524 \\
\hline 1 & 6 & 41.651 & 2.842 \\
\hline 2 & 3 & 15.416 & 1.768 \\
\hline 2 & 5 & 29.309 & 3.508 \\
\hline 4 & 6 & 9.040 & 0.104 \\
\hline 4 & 3 & 39.584 & 0.000 \\
\hline 6 & 5 & 0.691 & 0.000 \\
\hline \multicolumn{3}{|c}{ Total system loss } \\
\hline
\end{tabular}

Fig.2. Line diagram of six-bus system

It is stated earlier that to apply this method, a solved power flow of the system is needed. A Matlab program is developed and using the Newton-Raphson method the power flow solutions of the system is worked out. The results of receiving end active powers and the active power losses are shown in Table 1(a) above. 


\section{A.1. Procedure to formulate matrix $\left[F_{\text {active }}\right]$ or $\left[f_{i, j}\right]$}

Matrix $\left[f_{i, j}\right]$ is the contribution of line flows to loads. The number of rows of matrix $\left[f_{i, j}\right]$ equals with the number of load bus and the number of columns equals with the number of lossy branches of the system. In this test system, the lossy branches are (1-4), (1-6), (2-3), (2-5), and (4-6). The load buses are 3, 5 and 6 . Though different methods are available [15] for power flow tracing to find the contributions of line flows, here the mostly used proportional sharing method is taken into consideration. The details of this method have been described below.

\section{A.2. Proportional sharing method}

In the proportional sharing method, it is assumed that power flowing in to the node can be considered as the proportional sum of the power flowing out of the node. Fig.3 illustrates the method.

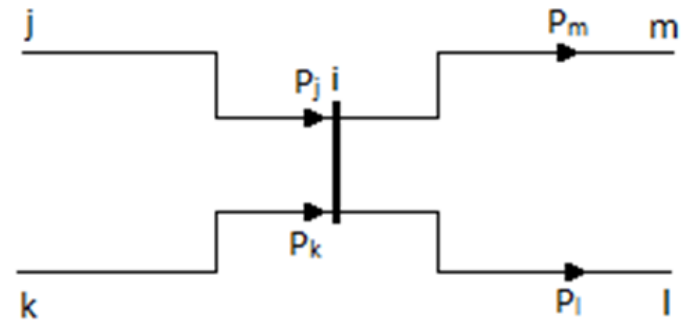

Fig.3. Illustration of proportional sharing method

Here ' $i$ ' is taken as the junction node where $(j-i),(k-i)$ are incoming lines and (i-m), $(i-l)$ are outgoing lines. $P_{j}$, $P_{k}$ are the receiving powers and $P_{m}, P_{l}$ are the outgoing powers at node ' $i$ '.

By proportional sharing principle, each outgoing line takes the power from each incoming line in proportion to its multiplying factor. Now from the above figure, the multiplying factor of line $(i-m)=\frac{P_{m}}{P_{j}+P_{k}}$; and the multiplying factor of line $(i-l)=\frac{P_{l}}{P_{j}+P_{k}}$. As total incoming power is equal with the total outgoing power at a node, so, $\left(P_{j}+P_{k}\right)=\left(P_{m}+P_{l}\right)$ at the node ' $i$ '. This relation may be used in the above expressions of calculation of multiplying factors. Thus, contribution of incoming power ' $P_{j}^{\prime}$ to the outgoing line $(i-m)=\frac{P_{m}}{P_{m}+P_{l}} \times$ $P_{j}$. Similarly, contribution of incoming power ' $P_{j}^{\prime}$ to the outgoing line $(i-l)=\frac{P_{l}}{P_{m}+P_{l}} \times P_{j}$. This is repeated for other lines also.

\section{A.3. Implementation of proportional sharing method to formulate matrix, $\left[F_{\text {active }}\right]$}

Step-1: Calculation of multiplying factors of lines and loads by taking active data from the load flow solution. Step-2: Calculation of power flow contribution of the lossy line to the load.

Step-3: Formation of matrix, $\left[f_{i, j}\right]$ by taking the power flow contributions of lossy branches into load buses.

\section{A.4. Calculation of multiplying factors}

While calculating the multiplying factors for the different lines, emphasis must be given to choose the particular bus which has more than one outgoing lines and simultaneously acting as a mediatory path for the power flow. In the six-bus system, bus 4 and bus 6 are to be taken for the calculation of multiplying factors.

Bus 4

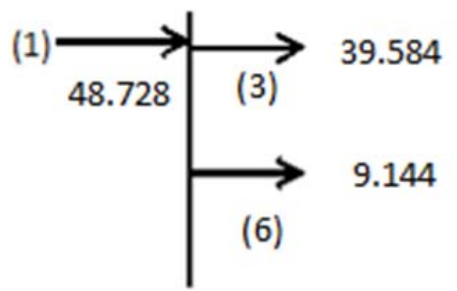

Total output $=39.584+9.144=48.728$

Multiplying factor of (4-3) line $=\frac{39.584}{48.728}=0.8123$

Multiplying factor of (4-6) line $=\frac{9.144}{48.728}=0.1877$

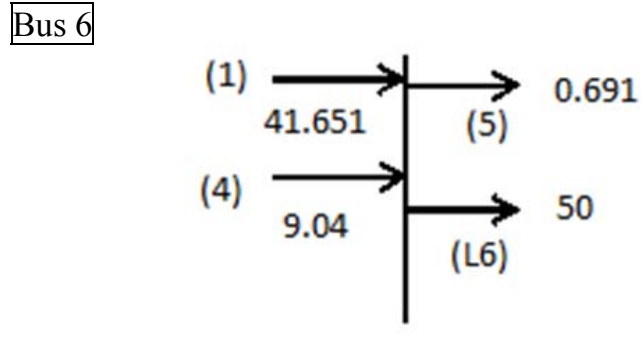

Total output $=0.691+50=50.691$

Multiplying factor of (6-5) line $=\frac{0.691}{50.691}=0.0136$

Multiplying factor of load L6 $=\frac{50}{50.691}=0.9863$ 


\section{A.5. Calculation of power flow contribution}

Now based on the multiplying factors and topology of the system, contributions of different lines towards the different loads are to be worked out. In six-bus case, the load buses are 3, 5 and 6.

\section{For load bus 3}

Contribution of (2-3) line $=15.416$

Contribution of (1-4) line $=39.584$

\section{For load bus 5}

Contribution of (2-5) line $=29.309$

Contribution of (1-6) line $=41.651 \times 0.0136=0.566$

Contribution of (4-6) line $=9.04 \times 0.0136=0.123$

Contribution of $(1-4)$ line $=48.728 \times 0.1877 \times 0.0136=0.124$

For Load Bus 6

Contribution of $(1-6)$ line $=41.651 \times 0.9863=41.08$

Contribution of $(4-6)$ line $=9.04 \times 0.9863=8.916$

Contribution of $(1-4)$ line $=48.728 \times 0.1877 \times 0.9863=9.02$

The contributions of line flows to different loads in the six-bus case are shown in Table 1(b).

Table 1(b) Contribution of line flows to loads

\begin{tabular}{|c|l|l|l|l|l|}
\hline $\begin{array}{c}\text { Load } \\
\text { Bus }\end{array}$ & \multicolumn{5}{|c|}{ Lossy Branch } \\
\hline & $1-4$ & $1-6$ & $2-3$ & $2-5$ & $4-6$ \\
\hline 3 & 39.584 & 0 & 15.416 & 0 & 0 \\
\hline 5 & 0.124 & 0.566 & 0 & 29.309 & 0.123 \\
\hline 6 & 9.02 & 41.08 & 0 & 0 & 8.916 \\
\hline
\end{tabular}

\section{A.6. Formation of matrix $\left[F_{\text {active }}\right]$}

From the data of Table 1(b), matrix $\left[F_{\text {active }}\right]$ is formed where rows and columns are listed by lossy branches (14), (1-6), (2-3), (2-5), (4-6) and load buses 3, 5, 6, respectively. Thus,

$$
\left[F_{\text {active }}\right]=\left[\begin{array}{ccccc}
39.584 & 0 & 15.416 & 0 & 0 \\
0.124 & 0.566 & 0 & 29.309 & 0.123 \\
9.02 & 41.08 & 0 & 0 & 8.916
\end{array}\right]
$$

\section{A.7. Computation of loss allocation}

Loss allocations to different loads have to be computed by using the Eq. (4). Now $\left[P_{R}\right]$ and $\left[P_{L}\right]$ matrices are formed by taking the data from Table 1 (a) such that $\left[P_{R}\right]=[48.728 ; 41.651 ; 15.416 ; 29.309 ; 9.04]$ and $\left[P_{L}\right]=$ $[2.524 ; 2.842 ; 1.768 ; 3.508 ; 0.104]$.

Therefore loss allocations to different loads are $\left[P_{\text {LOSS }}\right]_{i}=\left[\begin{array}{l}3.8184 \\ 3.5545 \\ 3.3728\end{array}\right]$; this column matrix shows the amount of loss allocations to the load buses 3, 5 and 6 in MW, respectively.

\section{A.8. Interpretation of results}

Table 1.(c) Comparison of loss allocations between four methods

\begin{tabular}{|c|c|c|c|c|}
\hline \multirow{2}{*}{$\begin{array}{c}\text { Load } \\
\text { bus no. }\end{array}$} & \multicolumn{4}{|c|}{ Different Methods } \\
\cline { 2 - 5 } & Pro-Rata & ITL & Method[22] & Proposed \\
\hline 3 & 4.377 & 4.194 & 3.853 & 3.8184 \\
\hline 5 & 2.388 & 2.300 & 3.638 & 3.5545 \\
\hline 6 & 3.979 & 4.250 & 3.253 & 3.3728 \\
\hline Total Loss & 10.744 & 10.7449 & 10.744 & 10.7457 \\
\hline
\end{tabular}

Table 1(c) shows the allocations of transmission loss to three different loads connected at buses 3, 5 and 6 along with the comparison between the three earlier methods with the proposed one. The result shows a big difference of loss allocation in particular to the load at bus 5. From the line diagram it is seen that the load at bus 5 is getting powers from bus 2 and 6 . Lossy lines (1-4), (1-6), and (4-6) are partially contributing power to load 5 
through bus 6, whereas, line (2-5) is exclusively contributing its total power from bus 2 to load 5. So, it is obvious that total loss incurred in line (2-5) and partial losses in other lines must be allocated to the load at bus 5. But, it is verified from the load flow solution in Table 1(a) that the loss occurred only in the line of (2-5) is 3.508MW. So, it justifies that the loss allocation to load at bus 5 must be higher than this value. Now in Table $1(\mathrm{c})$, it is observed that the loss allocated to load at bus 5 by Pro-Rata and ITL methods are 2.388MW and $2.300 \mathrm{MW}$, respectively which are quite below to the actual value. On the other hand, the other two methods including proposed method obtain the figures as $3.638 \mathrm{MW}$ and $3.5545 \mathrm{MW}$, respectively. This sounds reasonable. Also it is observed that the total active loss found from the load flow solution is also equal with the total loss allocated to different loads. Thus, it can be claimed that baring Pro-Rata and ITL, the other two methods are more accurate and its allocation of losses is justifiable. However, the method [22] is not giving suitable results in the higher order bus systems which are presented hereafter.

\section{B. Case Study-II (IEEE-14 Bus Test System)}

In the IEEE-14 bus system as shown in Fig.4, generators are attached to the buss 1 and 2 and loads are attached to buses $2,3,4,5,6,9,10,11,12,13$ and 14. Bus 1 is considered as the slack bus. The detailed data of this system have been adopted from reference [7]. Now using Newton-Raphson iterative technique, the load flow program in Matlab for the system was run and the results of receiving end active line flows, $P_{R}$ and active power loss, $P_{L}$ are presented in Table 2(a) above.

\section{B.1. Contribution of active line flows}

Here, buses $2,4,5,6,7,9,11,12$, and 13 are considered for obtaining multiplying factors and lossy lines are identified as (1-2), (2-3), (2-4), (1-5), (2-5), (4-3), (5-4), (9-10), (6-11), (6-12), (6-13), (9-14), (11-10), (12-13), (13-14). Then by adopting the procedure as mentioned above, the calculation for contribution of active line flows are carried out and presented in Table $2(b)$ which shall be taken as $\left[F_{\text {active }}\right]$.

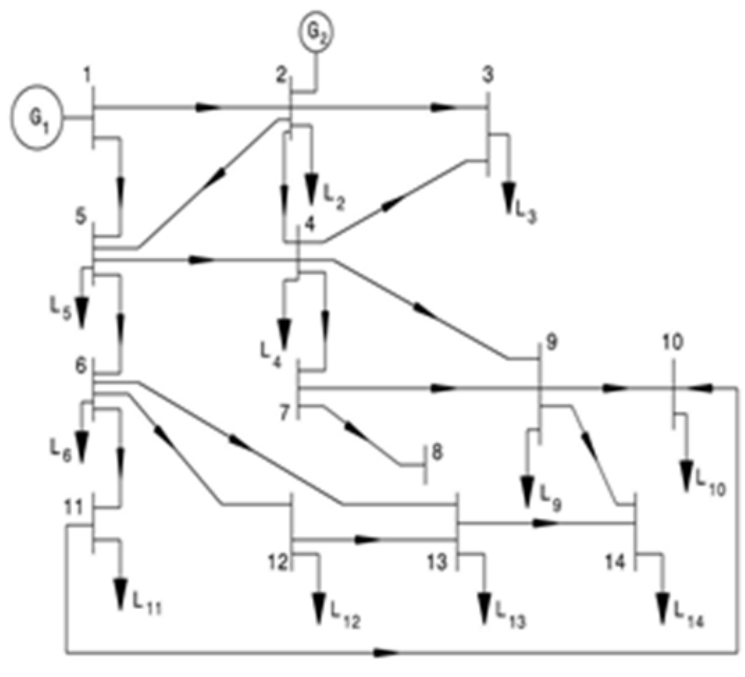

Table 2(a) Receiving end active line flows and active power loss of IEEE-14 bus test system

\begin{tabular}{|l|l|c|c|}
\hline \multicolumn{2}{|c|}{ Line } & $\begin{array}{c}\text { Receiving end active power } \\
\text { in } M W\end{array}$ & $\begin{array}{c}\text { Active loss in } \\
M W\end{array}$ \\
\hline From & To & $P_{R}$ & $P_{L}$ \\
\hline 1 & 2 & 152.705 & 4.305 \\
\hline 1 & 5 & 72.676 & 2.762 \\
\hline 2 & 3 & 71.035 & 2.331 \\
\hline 2 & 4 & 54.406 & 1.675 \\
\hline 2 & 5 & 40.616 & 0.907 \\
\hline 4 & 3 & 23.191 & 0.382 \\
\hline 5 & 4 & 60.991 & 0.504 \\
\hline 4 & 7 & 27.973 & 0.000 \\
\hline 4 & 9 & 16.003 & 0.000 \\
\hline 5 & 6 & 44.278 & 0.000 \\
\hline 6 & 11 & 7.398 & 0.061 \\
\hline 6 & 12 & 7.751 & 0.073 \\
\hline 6 & 13 & 17.609 & 0.216 \\
\hline 7 & 8 & 0.047 & 0.000 \\
\hline 7 & 9 & 27.946 & 0.000 \\
\hline 9 & 10 & 5.144 & 0.011 \\
\hline 9 & 14 & 9.210 & 0.111 \\
\hline 11 & 10 & 3.876 & 0.015 \\
\hline 12 & 13 & 1.649 & 0.007 \\
\hline 13 & 14 & 5.661 & 0.058 \\
\hline & & Total system loss & 13.419 \\
\hline & & & \\
\hline & & & 0 \\
\hline
\end{tabular}

\section{B.2. Computation of loss allocation}

Now the receiving end active power matrix, $\left[P_{R}\right]$ and active power loss matrix, $\left[P_{L}\right]$ are formed by taking the data from Table 2(a) for the lossy lines (1-2), (2-3), (2-4), (1-5), (2-5), (4-3), (5-4), (9-10), (6-11), (6-12), (6-13), (9-14), (11-10), (12-13), (13-14). Both are taken as column matrices. Thus, $\left[P_{R}\right]$ and $\left[P_{L}\right]$ are determined as: $\left[P_{R}\right]=$

[152.705;71.035;54.406;72.676;40.616;23.191;60.991;5.144;7.398;7.781;17.609;9.210;3.876;1.649;5.661] $\left[P_{L}\right]=[4.305 ; 2.331 ; 1.675 ; 2.762 ; 0.907 ; 0.382 ; 0.504 ; 0.011 ; 0.061 ; 0.073 ; 0.216 ; 0.111 ; 0.015 ; 0.007 ; 0.058]$

Now using the Eq. (4), the loss allocation for the different loads is worked out and presented in Table 2(c) along with the results worked out by the method [22]. Losses are taken in MW. 
Table 2(b) Active power flow tracing of IEEE-14 bus system

\begin{tabular}{|c|c|c|c|c|c|c|c|c|c|c|c|c|c|c|c|}
\hline \multirow{2}{*}{$\begin{array}{c}\text { Load } \\
\text { Bus }\end{array}$} & \multicolumn{15}{|c|}{ Lossy Branch } \\
\hline & $1-2$ & $2-3$ & $2-4$ & $1-5$ & $2-5$ & $4-3$ & $5-4$ & $9-10$ & $6-11$ & $6-12$ & $6-13$ & $9-14$ & $\begin{array}{l}11- \\
10\end{array}$ & $\begin{array}{l}12- \\
13\end{array}$ & $\begin{array}{l}13- \\
14\end{array}$ \\
\hline 2 & 17.2 & 0 & 0 & 0 & 0 & 0 & 0 & 0 & 0 & 0 & 0 & 0 & 0 & 0 & 0 \\
\hline 3 & 70.8578 & 71.035 & 11.0988 & 8.0355 & 4.49 & 23.191 & 12.442 & 0 & 0 & 0 & 0 & 0 & 0 & 0 & 0 \\
\hline 4 & 25.7863 & 0 & 22.524 & 16.307 & 9.11 & 0 & 25.25 & 0 & 0 & 0 & 0 & 0 & 0 & 0 & 0 \\
\hline 5 & 2.2 & 0 & 0 & 4.8692 & 2.721 & 0 & 0 & 0 & 0 & 0 & 0 & 0 & 0 & 0 & 0 \\
\hline 6 & 3.22 & 0 & 0 & 7.122 & 3.98 & 0 & 0 & 0 & 0 & 0 & 0 & 0 & 0 & 0 & 0 \\
\hline 9 & 15.8827 & 0 & 13.8735 & 10.04 & 5.612 & 0 & 15.552 & 0 & 0 & 0 & 0 & 0 & 0 & 0 & 0 \\
\hline 10 & 3.8826 & 0 & 2.3938 & 4.2571 & 2.3784 & 0 & 2.6836 & 5.144 & 3.898 & 0 & 0 & 0 & 3.898 & 0 & 0 \\
\hline 11 & 1.027 & 0 & 0 & 2.271 & 1.27 & 0 & 0 & 0 & 3.5 & 0 & 0 & 0 & 0 & 0 & 0 \\
\hline 12 & 1.76 & 0 & 0 & 3.8836 & 2.17 & 0 & 0 & 0 & 0 & 6.1 & 0 & 0 & 0 & 0 & 0 \\
\hline 13 & 3.9648 & 0 & 0 & 8.7405 & 4.8896 & 0 & 0 & 0 & 0 & 1.159 & 12.361 & 0 & 0 & 1.158 & 0 \\
\hline 14 & 6.6654 & 0 & 4.3524 & 6.8655 & 3.8356 & 0 & 4.8792 & 0 & 0 & 0.491 & 5.247 & 9.210 & 0 & 0.491 & 5.661 \\
\hline
\end{tabular}

Table 2(c) Results of loss allocation in IEEE-14 bus system

\begin{tabular}{|c|c|c|c|c|c|c|c|c|c|c|c|c|}
\hline $\begin{array}{c}\text { Load } \\
\text { Buses }\end{array}$ & 2 & 3 & 4 & 5 & 6 & 9 & 10 & 11 & 12 & 13 & 14 & Total \\
\hline Method[22] & 0.7225 & 5.5261 & 2.4245 & 0.3085 & 0.4630 & 1.4883 & 0.4779 & 0.1747 & 0.3037 & 0.7297 & 0.9439 & 13.5628 \\
\hline Proposed & 0.4849 & 5.5608 & 2.4522 & 0.3078 & 0.4503 & 1.5103 & 0.4785 & 0.1725 & 0.3031 & 0.7206 & 0.9489 & 13.3899 \\
\hline
\end{tabular}

\section{B.3. Interpretation of results of IEEE-14 bus system}

It is seen that the total active loss found out by load flow solution as shown in Table 2(a) is 13.419MW. This must be equal with the total loss allocations to different loads. But, it is observed that the mismatch obtained by the method [22] is $0.1438 \mathrm{MW}$ whereas by proposed method is $0.0291 \mathrm{MW}$ only. Hence, it is justified that the proposed method gives better result for the IEEE-14 bus system.

\section{Case Study-III (IEEE-30 Bus Test System)}

IEEE-30 test bus system having generators attached to buses 1,2 and loads to 2, 3, 4, 5, 7, 8, 10, 12, 14, 15, 16, $17,18,19,20,21,23,24,26,29,30$ is shown in Fig.5. The detailed data of its transformer tap settings, shunt capacitors, buses and lines have been adopted from reference [27]. Using Newton-Raphson iterative technique, the load flow program for the IEEE-30 bus system was run in Matlab. The results of receiving end active line flows and active line losses of different lines are given in Table 3(a) along with the total loss of the system.

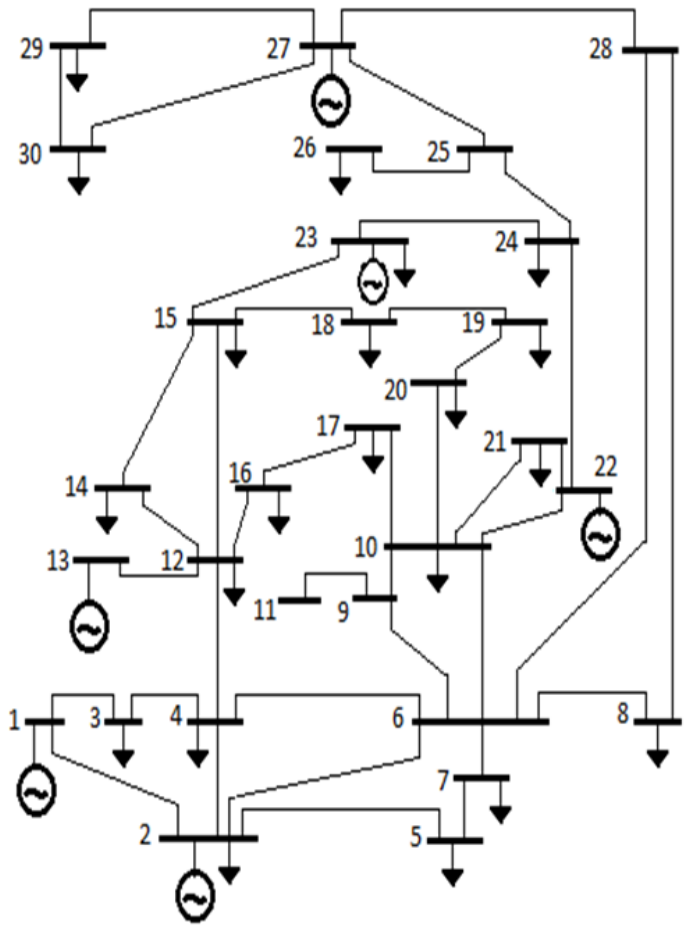

Fig.5. Line diagram of IEEE-30 bus test system
Table 3(a) Receiving end active line flows and active line loss of IEEE-30 bus test system

\begin{tabular}{|c|c|c|c|}
\hline \multicolumn{2}{|c|}{ Line } & Receiving end active power & Active loss in \\
\hline From & To & $\mathrm{P}_{\mathrm{R}}$ & $\mathrm{P}_{\mathrm{L}}$ \\
\hline 1 & 2 & 172.282 & 5.461 \\
\hline 1 & 3 & 80.390 & 2.807 \\
\hline 2 & 4 & 44.596 & 1.106 \\
\hline 2 & 5 & 79.995 & 2.995 \\
\hline 2 & 6 & 59.858 & 2.047 \\
\hline 3 & 4 & 77.263 & 0.771 \\
\hline 4 & 6 & 69.527 & 0.605 \\
\hline 4 & 12 & 44.131 & 0.000 \\
\hline 7 & 5 & 14.210 & 0.151 \\
\hline 6 & 7 & 37.170 & 0.368 \\
\hline 6 & 8 & 29.431 & 0.103 \\
\hline 6 & 9 & 27.687 & 0.000 \\
\hline 6 & 10 & 15.828 & 0.000 \\
\hline 6 & 28 & 18.780 & 0.060 \\
\hline 28 & 8 & 0.570 & 0.000 \\
\hline 9 & 11 & 0.003 & 0.000 \\
\hline 9 & 10 & 27.731 & 0.000 \\
\hline 10 & 20 & 8.937 & 0.081 \\
\hline 10 & 17 & 5.332 & 0.014 \\
\hline 10 & 21 & 15.613 & 0.110 \\
\hline 10 & 22 & 7.531 & 0.052 \\
\hline 13 & 12 & 0.021 & 0.000 \\
\hline 12 & 14 & 7.778 & 0.074 \\
\hline 12 & 15 & 17.634 & 0.217 \\
\hline 12 & 16 & 7.152 & 0.053 \\
\hline 14 & 15 & 1.586 & 0.006 \\
\hline
\end{tabular}




\begin{tabular}{|l|l|l|l|}
\hline 15 & 18 & 5.970 & 0.039 \\
\hline 15 & 23 & 4.972 & 0.031 \\
\hline 16 & 17 & 3.646 & 0.012 \\
\hline 18 & 19 & 2.774 & 0.005 \\
\hline 20 & 19 & 6.703 & 0.017 \\
\hline 22 & 21 & 1.849 & 0.001 \\
\hline 22 & 24 & 5.601 & 0.043 \\
\hline 23 & 24 & 1.765 & 0.006 \\
\hline 25 & 24 & 1.322 & 0.008 \\
\hline 25 & 26 & 3.476 & 0.044 \\
\hline 27 & 25 & 4.866 & 0.026 \\
\hline 28 & 27 & 18.192 & 0.000 \\
\hline 27 & 29 & 6.093 & 0.086 \\
\hline 27 & 30 & 6.932 & 0.162 \\
\hline 29 & 30 & 3.683 & 0.034 \\
\hline & \multicolumn{3}{|c|}{ Total system loss } \\
\hline
\end{tabular}

\section{C.1. Contribution of active line flows}

In this system, buses $2,3,4,6,7,9,10,12,14,15,16,18,20,22,23,25,27,28$ and 29 are taken for calculation of multiplying factors. Lines (1-2), (1-3), (2-4), (3-4), (2-5), (2-6), (4-6), (7-5), (6-7), (6-8), (12-14), (12-15), (12-16), (14-15), (16-17), (15-18), (18-19), (20-19), (10-20), (10-17), (10-21), (10-22), (22-21), (15-23), (2224), (23-24), (25-24), (25-26), (27-25), (27-29), (27-30), (29-30) and (6-28) are identified as lossy lines. By using proportional sharing method and adopting the earlier procedure, the active power contributions of different lossy lines to loads are worked out. With respect to the load buses $2,3,4,5,7,8,10,12,14,15,16,17$, $18,19,20,21,23,24,26,29$ and 30, Tables 3(b), 3(c) and 3(d) show the contributions of lossy lines [(1-2), (1$3),(2-4),(3-4),(2-5),(2-6),(4-6),(7-5),(6-7),(6-8),(12-14)] ;[(12-15),(12-16),(14-15),(16-17),(15-18),(18-$ $19),(20-19),(10-20),(10-17),(10-21),(10-22)]$ and [(22-21), (15-23), (22-24), (23-24), (25-24), (25-26), (2725), (27-29), (27-30), (29-30), (6-28)], respectively. It is to be noted here that due to insufficient space for presenting the contribution of line flows in one table, the results are tabulated in three tables i.e., from line (1-2) to line (12-14) in Table 3(b), from line (12-15) to line (10-22) in Table 3(c) and from line (22-21) to line (6-28) in Table $3(\mathrm{~d})$. These results constitute active power tracing matrix $\left[F_{\text {active }}\right]$.

Table 3(b) Contribution of active line flows to loads in IEEE-30 bus system for line (1-2) to line (12-14)

\begin{tabular}{|c|c|c|c|c|c|c|c|c|c|c|c|}
\hline Load bus & \multicolumn{11}{|c|}{ Lossy Branch } \\
\hline & $1-2$ & $1-3$ & $2-4$ & $3-4$ & $2-5$ & $2-6$ & $4-6$ & $7-5$ & $6-7$ & $6-8$ & $12-14$ \\
\hline 2 & 17.573 & 0 & 0 & 0 & 0 & 0 & 0 & 0 & 0 & 0 & 0 \\
\hline 3 & 0 & 2.3956 & 0 & 0 & 0 & 0 & 0 & 0 & 0 & 0 & 0 \\
\hline 4 & 2.3113 & 4.8658 & 2.78279 & 4.8212 & 0 & 0 & 0 & 0 & 0 & 0 & 0 \\
\hline 5 & 75.2093 & 5.028 & 2.8754 & 4.9817 & 79.995 & 6.7 & 7.783 & 14.21 & 14.348 & 0 & 0 \\
\hline 7 & 12.7358 & 7.985 & 4.5664 & 7.9114 & 0 & 10.641 & 12.36 & 0 & 22.785 & 0 & 0 \\
\hline 8 & 16.3343 & 10.2412 & 5.8567 & 10.1468 & 0 & 13.6476 & 15.8522 & 0 & 0 & 29.431 & 0 \\
\hline 10 & 3.2095 & 2.0123 & 1.1508 & 1.9938 & 0 & 2.6816 & 3.11481 & 0 & 0 & 0 & 0 \\
\hline 12 & 3.4041 & 7.1664 & 4.0985 & 7.1007 & 0 & 0 & 0 & 0 & 0 & 0 & 0 \\
\hline 14 & 1.8872 & 3.9731 & 2.2722 & 3.9366 & 0 & 0 & 0 & 0 & 0 & 0 & 6.1913 \\
\hline 15 & 2.5237 & 5.3129 & 3.0384 & 5.2641 & 0 & 0 & 0 & 0 & 0 & 0 & 0.6773 \\
\hline 16 & 1.0818 & 2.2775 & 1.3025 & 2.2566 & 0 & 0 & 0 & 0 & 0 & 0 & 0 \\
\hline 17 & 4.087 & 4.2303 & 2.4193 & 4.19143 & 0 & 2.4721 & 2.8715 & 0 & 0 & 0 & 0 \\
\hline 18 & 0.9898 & 2.0837 & 1.1917 & 2.0646 & 0 & 0 & 0 & 0 & 0 & 0 & 0.2656 \\
\hline 19 & 4.6184 & 4.1646 & 2.3817 & 4.1263 & 0 & 3.1415 & 3.649 & 0 & 0 & 0 & 0.2304 \\
\hline 20 & 1.2318 & 0.7723 & 0.4417 & 0.7652 & 0 & 1.0292 & 1.1954 & 0 & 0 & 0 & 0 \\
\hline 21 & 9.7895 & 6.1379 & 3.5102 & 6.0814 & 0 & 8.1794 & 9.5007 & 0 & 0 & 0 & 0 \\
\hline 23 & 0.9891 & 2.0823 & 1.1909 & 2.0632 & 0 & 0 & 0 & 0 & 0 & 0 & 0.2655 \\
\hline 24 & 4.48 & 3.618 & 2.0691 & 3.5848 & 0 & 3.2857 & 3.8165 & 0 & 0 & 0 & 0.1469 \\
\hline 26 & 2.042 & 1.28 & 0.7321 & 1.26835 & 0 & 1.70595 & 1.9815 & 0 & 0 & 0 & 0 \\
\hline 29 & 1.3906 & 0.87168 & 0.4985 & 0.8637 & 0 & 1.1617 & 1.3494 & 0 & 0 & 0 & 0 \\
\hline 30 & 6.2276 & 3.9037 & 2.2324 & 3.8679 & 0 & 5.2024 & 6.0431 & 0 & 0 & 0 & 0 \\
\hline
\end{tabular}

Table 3(c) Contribution of active line flows to loads in IEEE-30 bus system for line (12-15) to line (10-22)

\begin{tabular}{|c|c|c|c|c|c|c|c|c|c|c|c|}
\hline Load bus & \multicolumn{11}{|c|}{ Lossy Branch } \\
\hline & $12-15$ & $12-16$ & 14-15 & 16-17 & $15-18$ & $18-19$ & $20-19$ & $10-20$ & $10-17$ & $10-21$ & $10-22$ \\
\hline 2 & 0 & 0 & 0 & 0 & 0 & 0 & 0 & 0 & 0 & 0 & 0 \\
\hline 3 & 0 & 0 & 0 & 0 & 0 & 0 & 0 & 0 & 0 & 0 & 0 \\
\hline 4 & 0 & 0 & 0 & 0 & 0 & 0 & 0 & 0 & 0 & 0 & 0 \\
\hline 5 & 0 & 0 & 0 & 0 & 0 & 0 & 0 & 0 & 0 & 0 & 0 \\
\hline 7 & 0 & 0 & 0 & 0 & 0 & 0 & 0 & 0 & 0 & 0 & 0 \\
\hline 8 & 0 & 0 & 0 & 0 & 0 & 0 & 0 & 0 & 0 & 0 & 0 \\
\hline 10 & 0 & 0 & 0 & 0 & 0 & 0 & 0 & 0 & 0 & 0 & 0 \\
\hline
\end{tabular}




\begin{tabular}{|l|l|l|l|l|l|l|l|l|l|l|l|}
\hline 12 & 0 & 0 & 0 & 0 & 0 & 0 & 0 & 0 & 0 & 0 & 0 \\
\hline 14 & 0 & 0 & 0 & 0 & 0 & 0 & 0 & 0 & 0 & 0 & 0 \\
\hline 15 & 7.5297 & 0 & 0.6772 & 0 & 0 & 0 & 0 & 0 & 0 & 0 & 0 \\
\hline 16 & 0 & 3.5045 & 0 & 0 & 0 & 0 & 0 & 0 & 0 & 0 & 0 \\
\hline 17 & 0 & 3.6548 & 0 & 3.646 & 0 & 0 & 0 & 0 & 5.332 & 0 & 0 \\
\hline 18 & 2.9531 & 0 & 0.2656 & 0 & 3.19395 & 0 & 0 & 0 & 0 & 0 & 0 \\
\hline 19 & 2.5612 & 0 & 0.2304 & 0 & 2.7701 & 2.774 & 6.703 & 6.7296 & 0 & 0 & 0 \\
\hline 20 & 0 & 0 & 0 & 0 & 0 & 0 & 0 & 2.2048 & 0 & 0 & 0 \\
\hline 21 & 0 & 0 & 0 & 0 & 0 & 0 & 0 & 0 & 0 & 15.613 & 1.8828 \\
\hline 23 & 2.9513 & 0 & 0.2654 & 0 & 0 & 0 & 0 & 0 & 0 & 0 & 0 \\
\hline 24 & 1.6335 & 0 & 0.1469 & 0 & 0 & 0 & 0 & 0 & 0 & 0 & 5.6708 \\
\hline 26 & 0 & 0 & 0 & 0 & 0 & 0 & 0 & 0 & 0 & 0 & 0 \\
\hline 29 & 0 & 0 & 0 & 0 & 0 & 0 & 0 & 0 & 0 & 0 & 0 \\
\hline 30 & 0 & 0 & 0 & 0 & 0 & 0 & 0 & 0 & 0 & 0 & 0 \\
\hline
\end{tabular}

\section{C.2. Computation of loss allocation}

Receiving end active power matrix, $\left[P_{R}\right]$ and active power loss matrix, $\left[P_{L}\right]$ have been formulated by taking the data from Table 3(a) for the lossy lines (1-2), (1-3), (2-4), (3-4), (2-5), (2-6), (4-6), (7-5), (6-7), (6-8), (12-14), (12-15), (12-16), (14-15), (16-17), (15-18), (18-19), (20-19), (10-20), (10-17), (10-21), (10-22), (22-21), (1523), (22-24), (23-24), (25-24), (25-26), (27-25), (27-29), (27-30), (29-30) and (6-28). Both $\left[P_{R}\right]$ and $\left[P_{L}\right]$ are column matrices and whose values are given below.

$\left[P_{R}\right]=$

$[172.282 ; 80.39 ; 44.596 ; 77.263 ; 79.995 ; 59.858 ; 69.527 ; 14.210 ; 37.170 ; 29.431 ; 7.778 ; 17.634 ; 7.152 ; 1.586 ; 3.646 ; 5.9$ $70 ; 2.774 ; 6.703 ; 8.937 ; 5.332 ; 15.613 ; 7.531 ; 1.849 ; 4.972 ; 5.601 ; 1.765 ; 1.322 ; 3.476 ; 4.866 ; 6.093 ; 6.932 ; 3.683 ; 18.780$ ]

$\left[P_{L}\right]=$

$[5.461 ; 2.807 ; 1.106 ; 0.771 ; 2.995 ; 2.047 ; 0.605 ; 0.151 ; 0.368 ; 0.103 ; 0.074 ; 0.217 ; 0.053 ; 0.006 ; 0.012 ; 0.039 ; 0.005 ;$ $0.017 ; 0.081 ; 0.014 ; 0.110 ; 0.052 ; 0.001 ; 0.031 ; 0.043 ; 0.006 ; 0.008 ; 0.044 ; 0.026 ; 0.086 ; 0.162 ; 0.034 ; 0.06]$

Now using the Eq. (4), the loss allocation to all the load buses have been calculated and presented in Table 3(e). Loss allocation by the method [22] has also been given for a comparative study. All the loss values are taken in MW.

Table 3(d) Contribution of active line flows to loads in IEEE-30 bus system for line (22-21) to line (6-28)

\begin{tabular}{|l|l|l|l|l|l|l|l|l|l|l|l|l|l|}
\hline Load bus & \multicolumn{9}{|c|}{ Lossy Branch } \\
\hline & $22-21$ & $15-23$ & $22-24$ & $23-24$ & $25-24$ & $25-26$ & $27-25$ & $27-29$ & $27-30$ & $29-30$ & $6-28$ \\
\hline 2 & 0 & 0 & 0 & 0 & 0 & 0 & 0 & 0 & 0 & 0 & 0 \\
\hline 3 & 0 & 0 & 0 & 0 & 0 & 0 & 0 & 0 & 0 & 0 & 0 \\
\hline 4 & 0 & 0 & 0 & 0 & 0 & 0 & 0 & 0 & 0 & 0 & 0 \\
\hline 5 & 0 & 0 & 0 & 0 & 0 & 0 & 0 & 0 & 0 & 0 & 0 \\
\hline 7 & 0 & 0 & 0 & 0 & 0 & 0 & 0 & 0 & 0 & 0 & 0 \\
\hline 8 & 0 & 0 & 0 & 0 & 0 & 0 & 0 & 0 & 0 & 0 & 0 \\
\hline 10 & 0 & 0 & 0 & 0 & 0 & 0 & 0 & 0 & 0 & 0 & 0 \\
\hline 12 & 0 & 0 & 0 & 0 & 0 & 0 & 0 & 0 & 0 & 0 & 0 \\
\hline 14 & 0 & 0 & 0 & 0 & 0 & 0 & 0 & 0 & 0 & 0 & 0 \\
\hline 15 & 0 & 0 & 0 & 0 & 0 & 0 & 0 & 0 & 0 & 0 & 0 \\
\hline 16 & 0 & 0 & 0 & 0 & 0 & 0 & 0 & 0 & 0 & 0 & 0 \\
\hline 17 & 0 & 0 & 0 & 0 & 0 & 0 & 0 & 0 & 0 & 0 & 0 \\
\hline 18 & 0 & 0 & 0 & 0 & 0 & 0 & 0 & 0 & 0 & 0 & 0 \\
\hline 19 & 0 & 0 & 0 & 0 & 0 & 0 & 0 & 0 & 0 & 0 & 0 \\
\hline 20 & 0 & 0 & 0 & 0 & 0 & 0 & 0 & 0 & 0 & 0 & 0 \\
\hline 21 & 1.849 & 0 & 0 & 0 & 0 & 0 & 0 & 0 & 0 & 0 & 0 \\
\hline 23 & 0 & 3.2 & 0 & 0 & 0 & 0 & 0 & 0 & 0 & 0 & 0 \\
\hline 24 & 0 & 1.7712 & 5.601 & 1.765 & 1.322 & 0 & 1.3343 & 0 & 0 & 0 & 1.3904 \\
\hline 26 & 0 & 0 & 0 & 0 & 0 & 3.476 & 3.5327 & 0 & 0 & 0 & 3.6812 \\
\hline 29 & 0 & 0 & 0 & 0 & 0 & 0 & 0 & 2.391 & 0 & 0 & 2.5069 \\
\hline 30 & 0 & 0 & 0 & 0 & 0 & 0 & 0 & 3.7022 & 6.932 & 3.683 & 11.2268 \\
\hline
\end{tabular}

\section{C.3. Interpretation of results of IEEE-30 bus system}

It is seen from Table 3(a) that the total active loss in IEEE-30 bus system is 17.594 MW. Now from Table 3(e), it is found out that the total allocated loss by method [22] is $22.2564 \mathrm{MW}$ and by the proposed method is 17.5901MW. As the total allocated loss to all the load buses cannot be more than the system loss, hence the proposed method sounds reasonable. 
Table 3(e) Results of loss allocations in IEEE-30 bus system

\begin{tabular}{|c|c|c|c|c|c|}
\hline \multirow{2}{*}{$\begin{array}{c}\text { Load } \\
\text { Bus No. }\end{array}$} & \multicolumn{2}{|c|}{ Methods } & Load & \multicolumn{2}{c|}{ Methods } \\
\cline { 2 - 3 } \cline { 5 - 6 } & Method[22] & Proposed & Bus No. & Method[22] & Proposed \\
\hline 2 & 1.1323 & 0.5570 & 18 & 0.2038 & 0.2150 \\
\hline 3 & 0.0965 & 0.0836 & 19 & 0.6947 & 0.6669 \\
\hline 4 & 0.3878 & 0.3603 & 20 & 0.1707 & 0.1502 \\
\hline 5 & 7.3572 & 6.2655 & 21 & 1.6770 & 1.1588 \\
\hline 7 & 2.5037 & 1.5717 & 23 & 0.2149 & 0.2140 \\
\hline 8 & 2.0083 & 1.8647 & 24 & 0.9136 & 0.6391 \\
\hline 10 & 0.4204 & 0.3392 & 26 & 0.6456 & 0.2832 \\
\hline 12 & 0.7470 & 0.5306 & 29 & 0.2970 & 0.1843 \\
\hline 14 & 0.3579 & 0.3531 & 30 & 1.0637 & 0.9215 \\
\hline 15 & 0.4913 & 0.4951 & Total & 22.2564 & 17.5901 \\
\hline 16 & 0.2216 & 0.1946 & & & \\
\hline 17 & 0.6514 & 0.5417 & & & \\
\hline
\end{tabular}

\section{APPLICATION OF RELATIVE ELECTRICAL DISTANCE (RED) CONCEPT FOR REDUCTION OF LOSSES}

The loss reduction by RED method does not require any extra component to connect in the power system. It gives the data to readjust the generations with a desired value so that there will be a minimum loss in the system.

\section{A. Concept of RED}

The concept of RED is based on the information of the relative distances between the generator and load buses in a system. It is always desired that a load is predominantly met by the nearest generator maintaining all the constraints as far as possible. The concept of relative electrical distances is derived from the transmission network admittance matrix. Considering a system with ' $N$ ' total number of buses; ' $G$ ' number of generator buses, the following matrix equation can be written.

$\left[\begin{array}{c}I_{G} \\ I_{L}\end{array}\right]=\left[\begin{array}{ll}Y_{G G} & Y_{G L} \\ Y_{L G} & Y_{L L}\end{array}\right]\left[\begin{array}{c}V_{G} \\ V_{L}\end{array}\right]$

Where, ' $L$ ', the number of load buses. $I_{G}, I_{L}$ and $V_{G}, V_{L}$ represent injected current and complex voltage vectors at the respective buses. $\left[Y_{G G}\right],\left[Y_{G L}\right],\left[Y_{L L}\right]$ and $\left[Y_{L G}\right]$, are corresponding portions of network admittance bus matrix. Rearranging the equation (5), we get,

$\left[\begin{array}{l}V_{L} \\ I_{G}\end{array}\right]=\left[\begin{array}{ll}Z_{L L} & F_{L G} \\ K_{G L} & Y_{G G}\end{array}\right]\left[\begin{array}{c}I_{L} \\ V_{G}\end{array}\right]$

Where, $F_{L G}=-\left[Y_{L L}\right]^{-1}\left[Y_{L G}\right]$

The columns and rows of $\left[F_{L G}\right]$ matrix correspond to the generator bus numbers and load bus numbers, respectively. The elements of this matrix are complex and it gives the information between the location of load nodes corresponding to generator nodes that is termed as relative electrical distance between load nodes and generator nodes. Basing on this, each load is well informed about the power that should be taken from each generator under normal and network contingencies. This matrix is used as the basis for the desired load sharing/generation rescheduling. Therefore the relative electrical distances, i.e., the relative locations of load nodes with respect to the generator nodes is given by,

$\left[R_{L G}\right]=[A]-$ abs $\left\{\left[F_{L G}\right]\right\}$

Where, $[A]$ is the matrix with $(N-G)$ rows and ' $G$ ' number of columns of all elements equal to ' 1 ' or unity. The imaginary part of $\left[F_{L G}\right]$ matrix elements is almost negligible, hence without any loss of generality, the desired proportions of generation for the desired load sharing/generation scheduling can be obtained from the $\left[F_{L G}\right]$ matrix and is given by,

$\left[D_{L G}\right]=\operatorname{abs}\left\{\left[F_{L G}\right]\right\}$

Thus the desired generation schedule $[D G S]$, for the $G^{\text {th }}$ generator is obtained by using the mathematical relation of

$[D G S]_{G}^{\text {th }}=\sum_{j=G+1}^{\text {No.of Buses }}\left(\left[D_{j G}\right] \times\left[P_{j}\right]\right)$

where, $\left[P_{j}\right]$ is the load at the $j^{\text {th }}$ load bus and $\left[D_{j G}\right]$ values are taken from the $\left[D_{L G}\right]$ matrix of the given network. 


\section{B. Loss Reduction and Allocations}

The following algorithm represents the detailed procedure for loss reduction and allocations for the system network based on RED.

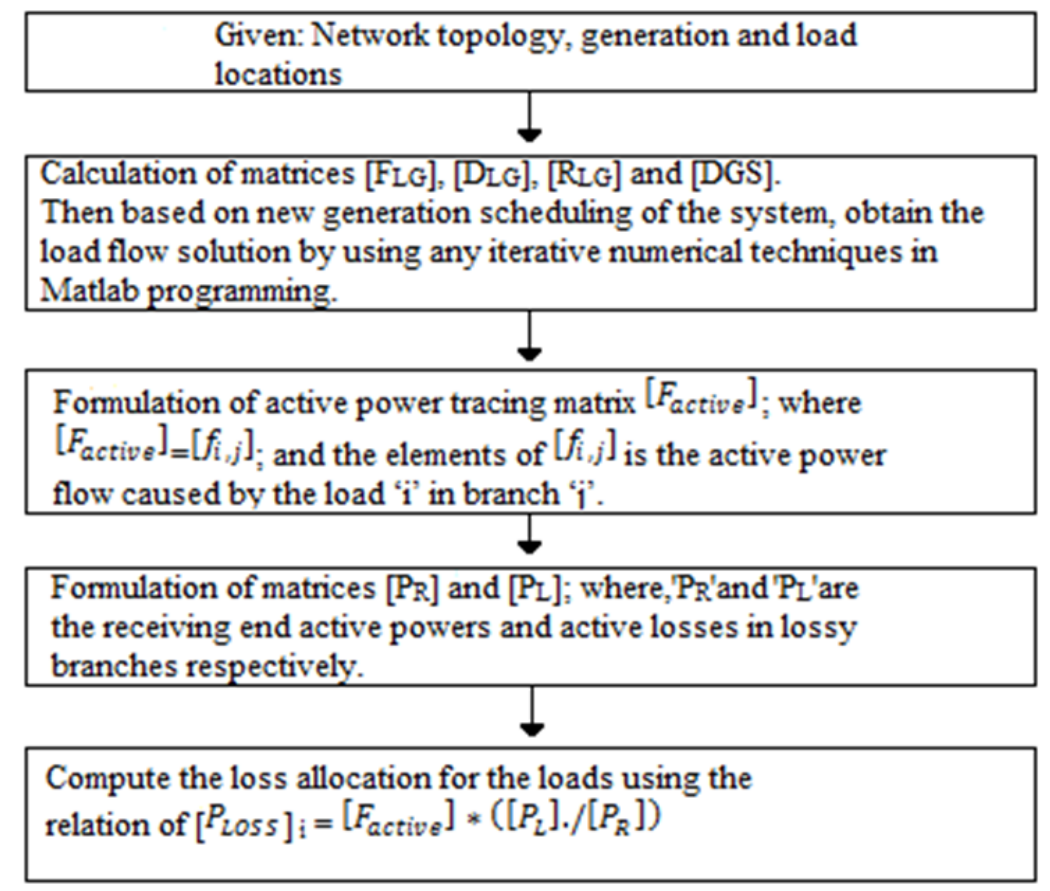

Fig.6. Flow chart for loss reduction and allocation using RED approach

\section{Case study of IEEE-14 bus system using RED concept}

\section{C.1. Calculation of [F $\left.F_{L G}\right],\left[D_{L G}\right]$, [R $\left.R_{L G}\right]$ and [DGS] matrices}

Adopting the line data from reference [7] and using the Eq. (7), the matrix $\left[F_{L G}\right]$ is computed and basing on its values the desired load sharing/generation scheduling matrix is derived by using Eq. (9). Finally the matrix $\left[D_{L G}\right]$ is shown in Table $4(\mathrm{a})$.

Table $4(a)\left[D_{L G}\right]$ matrix of IEEE-14 bus system

\begin{tabular}{|c|c|c|c|}
\hline \multirow{5}{*}{$\begin{array}{c}\text { Load Bus } \\
\text { No. }\end{array}$} & \multicolumn{2}{|c|}{ Generator Sharing } \\
\cline { 2 - 4 } & & $\mathrm{G} 1$ & $\mathrm{G} 2$ \\
\cline { 2 - 4 } & 3 & 0.1090 & 0.8910 \\
\cline { 2 - 4 } & 4 & 0.2069 & 0.7935 \\
\cline { 2 - 4 } & 5 & 0.2758 & 0.7247 \\
\cline { 2 - 4 } & 6 & 0.2532 & 0.7477 \\
\cline { 2 - 4 } & 9 & 0.2252 & 0.7751 \\
\cline { 2 - 4 } & 10 & 0.2301 & 0.7702 \\
\cline { 2 - 4 } & 11 & 0.2414 & 0.7591 \\
\cline { 2 - 4 } & 12 & 0.2511 & 0.7497 \\
\cline { 2 - 4 } & 13 & 0.2492 & 0.7516 \\
\cline { 2 - 4 } & 14 & 0.2356 & 0.7648 \\
\hline
\end{tabular}

Table 4(b) $\left[\mathrm{R}_{\mathrm{LG}}\right]$ matrix of IEEE-14 bus system

\begin{tabular}{|c|c|c|c|}
\hline \multirow{12}{*}[R_{LG}]{$=$} & \multirow{3}{*}{$\begin{array}{c}\text { Load Bus } \\
\text { No. } \\
\\
3\end{array}$} & \multicolumn{2}{|c|}{$\begin{array}{l}\text { Relative location of Load } \\
\text { node with respect to } \\
\text { Generator node }\end{array}$} \\
\hline & & G1 & G2 \\
\hline & & 0.8910 & 0.1090 \\
\hline & 4 & 0.7935 & 0.2069 \\
\hline & 5 & 0.7247 & 0.2758 \\
\hline & 6 & 0.7477 & 0.2532 \\
\hline & 9 & 0.7751 & 0.2252 \\
\hline & 10 & 0.7702 & 0.2301 \\
\hline & 11 & 0.7591 & 0.2414 \\
\hline & 12 & 0.7497 & 0.2511 \\
\hline & 13 & 0.7516 & 0.2492 \\
\hline & 14 & 0.7648 & 0.2356 \\
\hline
\end{tabular}

In the calculation of matrix $\left[D_{L G}\right]$, bus 2 is taken as the generator bus. Now relative electrical distance matrix $\left[R_{L G}\right]$ is found out by using Eq. (8) and the result is shown in Table 4(b) in above. Now the Desired Generation Scheduling at generator bus 1 and 2 are found out by using Eq. (10) and shown in Table 4(c). 
Table 4(c) [DGS] matrix of IEEE-14 bus system

\begin{tabular}{|c|c|c|c|}
\hline \multirow{1}{*}{$\begin{array}{c}\text { Load Bus } \\
\text { No. }\end{array}$} & \multicolumn{2}{|c|}{ Generator Scheduling } \\
\cline { 2 - 4 } & & $\mathrm{G} 1$ & $\mathrm{G} 2$ \\
\cline { 2 - 4 }$[\mathrm{DGS}]=$ & 3 & 10.2678 & 83.9322 \\
\cline { 2 - 4 } & 4 & 9.8898 & 37.9293 \\
\cline { 2 - 4 } & 5 & 2.0961 & 5.5077 \\
\cline { 2 - 4 } & 6 & 2.8358 & 8.3742 \\
\cline { 2 - 4 } & 9 & 6.6434 & 22.8654 \\
\cline { 2 - 4 } & 10 & 2.0709 & 6.9318 \\
\cline { 2 - 4 } & 11 & 0.8449 & 2.6568 \\
\hline & 12 & 1.5317 & 4.5732 \\
\hline & 13 & 3.3642 & 10.1466 \\
\hline & 14 & 3.5104 & 11.3955 \\
\hline & TOTAL & 43.055 & 194.3127 \\
\hline
\end{tabular}

Table 4(d) Receiving end active line flows and active power loss of

\begin{tabular}{|l|l|c|c|}
\hline \multicolumn{2}{|c|}{ Line } & $\begin{array}{c}\text { Receiving end active } \\
\text { power in } M W\end{array}$ & Active loss in $M W$ \\
\hline From & To & $\mathrm{P}_{\mathrm{R}}$ & $\mathrm{P}_{\mathrm{L}}$ \\
\hline 1 & 2 & 5.928 & 0.113 \\
\hline 1 & 5 & 44.759 & 1.065 \\
\hline 2 & 3 & 75.645 & 2.651 \\
\hline 2 & 4 & 64.083 & 2.348 \\
\hline 2 & 5 & 53.984 & 1.607 \\
\hline 4 & 3 & 18.555 & 0.241 \\
\hline 5 & 4 & 47.368 & 0.298 \\
\hline 4 & 7 & 28.529 & 0.000 \\
\hline 4 & 9 & 16.326 & 0.000 \\
\hline 5 & 6 & 43.387 & 0.000 \\
\hline 6 & 11 & 6.848 & 0.056 \\
\hline 6 & 12 & 7.680 & 0.072 \\
\hline 6 & 13 & 17.320 & 0.211 \\
\hline 7 & 8 & 0.000 & 0.000 \\
\hline 7 & 9 & 28.529 & 0.000 \\
\hline 9 & 10 & 5.665 & 0.013 \\
\hline 9 & 14 & 9.559 & 0.118 \\
\hline 11 & 10 & 3.335 & 0.013 \\
\hline 12 & 13 & 1.574 & 0.006 \\
\hline 13 & 14 & 5.341 & 0.053 \\
\hline \multicolumn{2}{|r|}{} & Total system loss & 8.865 \\
\hline
\end{tabular}

In the IEEE-14 bus system, bus 2 is attached to generator $G 2$ and load $L 2$. In desired load sharing calculation, G2 has been taken as generator bus so it is assumed that $G 2$ is supplying power to load $L 2$ directly from the bus 2 itself. Therefore, the above generator scheduling of $G 2$ must be added with the demand of load L2. So, the generation scheduling of generator 2 becomes, $G 2=194.3127+21.7=216.0127$ or $216 \mathrm{MW}$ (say).

\section{C.2. Calculation of load flow}

Rescheduling generator 2 at 216MW and using Newton-Raphson iterative technique with matlab programming, the load flow solution has been computed and the result is shown in Table 4(d) above.

\section{C.3. Result Interpretation}

From Table 2(a), it is seen that the total loss for the IEEE-14 bus system was $13.419 \mathrm{MW}$ and after applying the RED concept, the loss has been reduced to $8.865 \mathrm{MW}$ as shown in Table 4(d). So, the net amount of loss reduction in IEEE-14 bus is $4.554 \mathrm{MW}$.

\section{C.4. Calculation of Loss Allocations of IEEE-14 bus system}

For the loss allocations, all the procedures as stated earlier have been followed and the result is given in Table 4(e).

Table 4(e) Loss allocations after loss reduction in IEEE-14 bus system

\begin{tabular}{|c|c|c|c|c|c|c|c|c|c|c|c|c|}
\hline $\begin{array}{c}\text { Load } \\
\text { Buses }\end{array}$ & 2 & 3 & 4 & 5 & 6 & 9 & 10 & 11 & 12 & 13 & 14 & Total \\
\hline $\begin{array}{c}\text { Loss allocations } \\
\text { after loss } \\
\text { reduction in MW }\end{array}$ & 0.0111 & 3.6036 & 1.7092 & 0.2079 & 0.3065 & 1.0545 & 0.3488 & 0.1251 & 0.2256 & 0.5392 & 0.7321 & 8.8636 \\
\hline
\end{tabular}

\section{Case study of IEEE-30 bus system using RED concept}

\section{D.1 Calculation of $\left[F_{L G}\right],\left[D_{L G}\right],\left[R_{L G}\right]$ and [DGS] matrices}

Taking the line data from reference [27] and using the procedure as described above, the matrices $\left[D_{L G}\right],\left[R_{L G}\right]$, and $[D G S]$ are calculated and presented in Table 5(a), Table 5(b) and Table 5(c), respectively. 
Table 5(a) [DLG] matrix of IEEE-30 bus system

\begin{tabular}{|c|c|c|c|c|c|c|}
\hline \multirow{12}{*}[D_{LG}]{$=$} & \multirow{2}{*}{$\begin{array}{l}\text { Load Bus } \\
\quad \text { No. }\end{array}$} & \multicolumn{2}{|c|}{ Generator Sharing } & \multirow{2}{*}{$\begin{array}{l}\text { Load Bus } \\
\quad \text { No. }\end{array}$} & \multicolumn{2}{|c|}{ Generator Sharing } \\
\hline & & $G 1$ & $G 2$ & & $G 1$ & G2 \\
\hline & 3 & 0.4017 & 0.5991 & 17 & 0.2304 & 0.7698 \\
\hline & 4 & 0.2756 & 0.7247 & 18 & 0.2377 & 0.7627 \\
\hline & 5 & 0.1032 & 0.8968 & 19 & 0.2340 & 0.7663 \\
\hline & 7 & 0.1659 & 0.8342 & 20 & 0.2321 & 0.7682 \\
\hline & 8 & 0.2097 & 0.7906 & 21 & 0.2268 & 0.7734 \\
\hline & 10 & 0.2263 & 0.7739 & 23 & 0.2374 & 0.7629 \\
\hline & 12 & 0.2500 & 0.7506 & 24 & 0.2289 & 0.7714 \\
\hline & 14 & 0.2468 & 0.7537 & 26 & 0.2218 & 0.7784 \\
\hline & 15 & 0.2438 & 0.7566 & 29 & 0.2174 & 0.7828 \\
\hline & 16 & 0.2400 & 0.7603 & 30 & 0.2174 & 0.7828 \\
\hline
\end{tabular}

Table $5(b)\left[R_{L G}\right]$ matrix of IEEE-30 bus system

\begin{tabular}{|c|c|c|c|c|c|c|}
\hline \multirow{12}{*}[R_{LG}]{$=$} & \multirow[t]{2}{*}{$\begin{array}{l}\text { Load Bus } \\
\text { No. }\end{array}$} & \multicolumn{2}{|c|}{$\begin{array}{l}\text { Relative location of Load node } \\
\text { with respect to Generator node }\end{array}$} & \multirow[t]{2}{*}{$\begin{array}{l}\text { Load Bus } \\
\quad \text { No. }\end{array}$} & \multicolumn{2}{|c|}{$\begin{array}{l}\text { Relative location of Load } \\
\text { node with respect to } \\
\text { Generator node }\end{array}$} \\
\hline & & $G 1$ & $G 2$ & & $G 1$ & $G 2$ \\
\hline & 3 & 0.5991 & 0.4017 & 17 & 0.7698 & 0.2304 \\
\hline & 4 & 0.7247 & 0.2756 & 18 & 0.7627 & 0.2377 \\
\hline & 5 & 0.8968 & 0.1032 & 19 & 0.7663 & 0.2340 \\
\hline & 7 & 0.8342 & 0.1659 & 20 & 0.7682 & 0.2321 \\
\hline & 8 & 0.7906 & 0.2097 & 21 & 0.7734 & 0.2268 \\
\hline & 10 & 0.7739 & 0.2263 & 23 & 0.7629 & 0.2374 \\
\hline & 12 & 0.7506 & 0.2500 & 24 & 0.7714 & 0.2289 \\
\hline & 14 & 0.7537 & 0.2468 & 26 & 0.7784 & 0.2218 \\
\hline & 15 & 0.7566 & 0.2438 & 29 & 0.7828 & 0.2174 \\
\hline & 16 & 0.7603 & 0.2400 & 30 & 0.7828 & 0.2174 \\
\hline
\end{tabular}

Table 5(c) [DGS] matrix of IEEE-30 bus system

\begin{tabular}{|c|c|c|c|c|c|c|}
\hline \multirow{12}{*}[DGS]{$=$} & \multirow{2}{*}{$\begin{array}{l}\text { Load Bus } \\
\text { No. }\end{array}$} & \multicolumn{2}{|c|}{ Generator Scheduling } & \multirow{2}{*}{$\begin{array}{c}\text { Load Bus } \\
\text { No. }\end{array}$} & \multicolumn{2}{|c|}{ Generator Scheduling } \\
\hline & & G1 & $G 2$ & & G1 & G2 \\
\hline & 3 & 0.9640 & 1.4377 & 17 & 2.0740 & 6.9280 \\
\hline & 4 & 2.0945 & 5.5077 & 18 & 0.7605 & 2.4406 \\
\hline & 5 & 9.7190 & 84.4819 & 19 & 2.2231 & 7.2795 \\
\hline & 7 & 3.7832 & 19.0208 & 20 & 0.5106 & 1.6899 \\
\hline & 8 & 6.2918 & 23.7171 & 21 & 3.9682 & 13.5351 \\
\hline & 10 & 1.3123 & 4.4887 & 23 & 0.7597 & 2.4414 \\
\hline & 12 & 2.8004 & 8.4062 & 24 & 1.9910 & 6.7111 \\
\hline & 14 & 1.5304 & 4.6731 & 26 & 0.7763 & 2.7243 \\
\hline & 15 & 1.9993 & 6.2044 & 29 & 0.5218 & 1.8786 \\
\hline & 16 & 0.8401 & 2.6612 & 30 & 2.3045 & 8.2972 \\
\hline & & & & TOTAL & 47.2247 & 214.5245 \\
\hline
\end{tabular}

Bus 2 is attached to generator $G 2$ and load $L 2$. In desired load sharing calculation, $G 2$ is taken as the generator bus. Thus, $G 2$ is supplying power to load 2 directly from the bus 2 . Therefore, the above generator scheduling of $G 2$ must be added with the demand of load 2. So, the generator scheduling of $G 2=214.5245+21.7=236.2245$ or 236.3 MW (say).

\section{D.2. Calculation of load flow}

Taking generation of $G 2$ as $236.3 \mathrm{MW}$, the load flow solution is carried out using Newton-Raphson iterative technique with Matlab program and the result is shown below in Table 5(d). 
Table 5(d) Receiving end active line flows and active line loss of IEEE-30 Bus

\begin{tabular}{|c|c|c|c|c|c|c|c|}
\hline \multicolumn{2}{|c|}{ Line } & \multirow{2}{*}{$\begin{array}{c}\text { Receiving end active power in } \\
\text { MW }\end{array}$} & \multirow{2}{*}{$\begin{array}{c}\text { Active loss in } \\
\text { MW }\end{array}$} & \multicolumn{2}{|c|}{ Line } & \multirow{2}{*}{$\begin{array}{c}\text { Receiving end active power in } \\
\text { MW }\end{array}$} & \multirow{2}{*}{$\begin{array}{c}\text { Active loss in } \\
\text { MW } \\
P_{L}\end{array}$} \\
\hline From & To & & & From & To & & \\
\hline 1 & 2 & 7.705 & 0.151 & 13 & 12 & 0.042 & 0.000 \\
\hline 1 & 3 & 49.847 & 1.093 & 12 & 14 & 7.698 & 0.073 \\
\hline 2 & 4 & 58.932 & 1.942 & 12 & 15 & 17.207 & 0.209 \\
\hline 2 & 5 & 84.714 & 3.372 & 12 & 16 & 6.653 & 0.048 \\
\hline 2 & 6 & 70.460 & 2.873 & 14 & 15 & 1.455 & 0.005 \\
\hline 3 & 4 & 47.172 & 0.292 & 15 & 18 & 5.707 & 0.036 \\
\hline 4 & 6 & 55.049 & 0.372 & 15 & 23 & 4.661 & 0.029 \\
\hline 4 & 12 & 43.024 & 0.000 & 16 & 17 & 3.157 & 0.010 \\
\hline 7 & 5 & 9.476 & 0.082 & 18 & 19 & 2.509 & 0.004 \\
\hline 6 & 7 & 32.356 & 0.278 & 20 & 19 & 6.997 & 0.018 \\
\hline 6 & 8 & 29.449 & 0.104 & 22 & 21 & 1.744 & 0.001 \\
\hline 6 & 9 & 28.249 & 0.000 & 22 & 24 & 5.704 & 0.044 \\
\hline 6 & 10 & 16.142 & 0.000 & 23 & 24 & 1.486 & 0.005 \\
\hline 6 & 28 & 18.919 & 0.061 & 25 & 24 & 1.498 & 0.009 \\
\hline 28 & 8 & 0.531 & 0.000 & 25 & 26 & 3.484 & 0.044 \\
\hline 9 & 11 & 0.016 & 0.000 & 27 & 25 & 5.030 & 0.027 \\
\hline 9 & 10 & 28.253 & 0.000 & 28 & 27 & 18.377 & 0.000 \\
\hline 10 & 20 & 9.214 & 0.084 & 27 & 29 & 6.092 & 0.086 \\
\hline 10 & 17 & 5.840 & 0.016 & 27 & 30 & 6.926 & 0.161 \\
\hline 10 & 21 & 15.691 & 0.110 & 29 & 30 & 3.675 & 0.033 \\
\hline 10 & 22 & 7.586 & 0.052 & & & Total system loss & 11.727 \\
\hline
\end{tabular}

\section{D.3. Result Interpretation}

Total system loss of IEEE-30 bus was 17.594MW as shown in Table 3(a). Now after applying RED method, the total system loss has been reduced to $11.727 \mathrm{MW}$ as shown in Table $5(\mathrm{~d})$. So, there is a loss reduction of 5.867MW.

\section{D.4. Calculation of Loss Allocations of IEEE-30 bus system}

For the loss allocations, all the procedures as stated earlier have been followed and the results are given in Table 5(e) for the load buses 2 to 16 and in Table 5(f) for 17 to 30. The total loss of the system is shown in Table 5(f).

Table 5(e) Loss allocations after loss reduction in IEEE-30 bus system for load buses 2 to 16

\begin{tabular}{|c|c|c|c|c|c|c|c|c|c|c|c|}
\hline $\begin{array}{c}\text { Load } \\
\text { Buses }\end{array}$ & 2 & 3 & 4 & 5 & 7 & 8 & 10 & 12 & 14 & 15 & 16 \\
\hline $\begin{array}{c}\text { Loss allocations after loss } \\
\text { reduction in MW }\end{array}$ & 0.0134 & 0.0526 & 0.2373 & 3.9762 & 1.1154 & 1.3085 & 0.2318 & 0.3489 & 0.2549 & 0.3593 & 0.1348 \\
\hline
\end{tabular}

Table 5(f) Loss allocations after loss reduction in IEEE-30 bus system for load buses 17 to 30

\begin{tabular}{|c|c|c|c|c|c|c|c|c|c|c|c|}
\hline $\begin{array}{c}\text { Load } \\
\text { Buses }\end{array}$ & 17 & 18 & 19 & 20 & 21 & 23 & 24 & 26 & 29 & 30 & Total \\
\hline $\begin{array}{c}\text { Loss allocations after loss } \\
\text { reduction in MW }\end{array}$ & 0.3820 & 0.1611 & 0.4954 & 0.1088 & 0.8258 & 0.1600 & 0.4805 & 0.2168 & 0.1393 & 0.7173 & 11.7201 \\
\hline
\end{tabular}




\section{COMPARATIVE STUDY OF LOSS ALLOCATIONS}

The comparative figures of loss allocations before and after loss reduction by RED concept for IEEE-14 and IEEE-30 bus systems are presented in Table 6(a) and Table 6(b), respectively.

Table 6(a) Comparative figure of IEEE-14 bus system

\begin{tabular}{|c|c|c|}
\hline $\begin{array}{c}\text { Load } \\
\text { Bus } \\
\text { No. }\end{array}$ & $\begin{array}{c}\text { Loss allocations before } \\
\text { loss reduction } \\
\text { in MW }\end{array}$ & $\begin{array}{c}\text { Loss allocations after } \\
\text { loss reduction } \\
\text { in MW }\end{array}$ \\
\hline 2 & 0.4849 & 0.0111 \\
\hline 3 & 5.5608 & 3.6036 \\
\hline 4 & 2.4522 & 1.7092 \\
\hline 5 & 0.3078 & 0.2079 \\
\hline 6 & 0.4503 & 0.3065 \\
\hline 9 & 1.5103 & 1.0545 \\
\hline 10 & 0.4785 & 0.3488 \\
\hline 11 & 0.1725 & 0.1251 \\
\hline 12 & 0.3031 & 0.2256 \\
\hline 13 & 0.7206 & 0.5392 \\
\hline 14 & 0.9489 & 0.7321 \\
\hline Total & 13.3899 & 8.8636 \\
\hline
\end{tabular}

Table 6(b) Comparative figure of IEEE-30 bus system

\begin{tabular}{|c|c|c|}
\hline $\begin{array}{c}\text { Load } \\
\text { Bus } \\
\text { No. }\end{array}$ & $\begin{array}{l}\text { Loss allocations before } \\
\text { loss reduction } \\
\text { in MW }\end{array}$ & $\begin{array}{l}\text { Loss allocations after } \\
\text { loss reduction } \\
\text { in MW }\end{array}$ \\
\hline 2 & 0.5570 & 0.0134 \\
\hline 3 & 0.0836 & 0.0526 \\
\hline 4 & 0.3603 & 0.2373 \\
\hline 5 & 6.2655 & 3.9762 \\
\hline 7 & 1.5717 & 1.1154 \\
\hline 8 & 1.8647 & 1.3085 \\
\hline 10 & 0.3392 & 0.2318 \\
\hline 12 & 0.5306 & 0.3489 \\
\hline 14 & 0.3531 & 0.2549 \\
\hline 15 & 0.4951 & 0.3593 \\
\hline 16 & 0.1946 & 0.1348 \\
\hline 17 & 0.5417 & 0.3820 \\
\hline 18 & 0.2150 & 0.1611 \\
\hline 19 & 0.6669 & 0.4954 \\
\hline 20 & 0.1502 & 0.1088 \\
\hline 21 & 1.1588 & 0.8258 \\
\hline 23 & 0.2140 & 0.1600 \\
\hline 24 & 0.6391 & 0.4805 \\
\hline 26 & 0.2832 & 0.2168 \\
\hline 29 & 0.1843 & 0.1393 \\
\hline 30 & 0.9215 & 0.7173 \\
\hline Total & 17.5901 & 11.7201 \\
\hline
\end{tabular}

\section{CONCLUSION}

This paper analyzes the importance of loss allocation and loss reduction in deregulated power system. It finds the mismatch in loss allocation by some of the widely used methods and proposes a new formula for loss allocation. The new proposed formula is based on the physical flow of power. The main logic behind this formula is the segregation of each lossy line into as many sub-lines depending upon the numbers of loads attached to it, either directly or indirectly. Then total loss of the common line is divided among the loads with proportionate to their power receiving. Hence, it gives more justification to the load attached into the system. The new formula is used in a six-bus system and proves its viability. In addition it is also applied to IEEE-14 and IEEE-30 bus systems to allocate the losses among different loads. The relative electrical distance concept is used to reduce the loss in both IEEE-14 and IEEE-30 bus systems. In both the cases a significant reduction in loss is obtained. After reduction in system loss, again the loss allocations for the different loads are carried out and the results show a sufficient loss reduction in almost all the load buses. As the tariff and other economic considerations are mainly based on active power loss so, the efforts may be made to deal with these problems using the proposed method.

\section{REFERENCES}

[1] M.O.Oke, O.M.Bamigbola, "Minimization of losses on electric power transmission lines", Mathematical Theory and Modeling, Vol.3, No.7, 2013, pp.28-31.

[2] E.S.Ibrahim, "Management of loss reduction projects for power distribution systems", Electric Power Systems Research, Vol.55, 2000, pp.49-56.

[3] Y.Yu, Tongdanjin, C.Zhong, C.Wang, "A multi-agent based design of bidding mechanism for transmission loss reduction", Electrical Power and Energy Systems, Vol.78, 2016, pp.846-856.

[4] W.M.D.Rosa, P.Rossoni, J.C.Teixeira, E.A.Belati, "Insertion of wind generators in electrical power systems aimed at active losses reduction using sensitivity analysis”, Electrical Power and Energy Systems, Vol.80, 2016, pp.306-311 . 
[5] A.J.Canejo, J.M.Arroyo, N.Alguacil, A.L.Guijarro, "Transmission loss allocation: a comparison of different practical algorithms", IEEE Trans. on Power Syst., Vol.17, August-2002, pp.571-576.

[6] A.G.Exposito, J.M.R. Santos, T.G.Garcia, E.R.Velasco, "Fair allocation of transmission power losses", IEEE Trans. on Power Syst., Vol.15, February-2000, pp.184-188.

[7] A.J.Canejo, F.D.Galiana, I.Kockar, "Z-buss loss allocation”, IEEE Trans. on Power Syst., Vol.16, No.1, February-2001, pp.105-110.

[8] A.Canejo, N.Alguacil, G.F.Ruiz, "Allocation of the cost of transmission losses using a radial equivalent network", IEEE Trans. on Power Syst., Vol.18, November-2003, pp.1353-1358.

[9] P.N.Bisnas, A.Tsakoumis, A.G.Bakirtzis, A.Koronides, J.Kabouris, "Transmission loss allocation through zonal aggregation", Electric Power Systems Research, Vol.81, 2011, pp.1973-1985.

[10] N.B.Dev Choudhury, A.Chatterjee, S.K.Goswami, "A fuzzy membership filtering aided neural network based transmission loss allocation scheme using game theory", Expert Systems with Applications, Vol.39, 2012, pp. 3162-3168.

[11] B.Khan, G.Agnihotri, "Optimal transmission network usage and loss allocation using matrices methodology and cooperative game theory", International Journal of Electrical, Computer, Energetic and Communication Engineering, Vol.7, No.2, 2013, pp.196-204.

[12] C.G.Beckman, "India's new cost allocation method for inter-state transmission: Implications for the future of the Indian electricity sector", The Electricity Journal, Vol.26, Issue-10, December-2013, pp.40-50.

[13] G.Gross, S.Tao, "A physical-flow-based approach to allocating transmission losses in a transaction framework", IEEE Trans. on Power Syst., Vol.15, No.2, May-2000, pp.631-637.

[14] G.Strbac, D.Kirschen, S.Ahmed, "Allocating transmission system usage on the basis of traceable contributions of generators and loads to flows", IEEE Trans. on Power Syst., Vol.13, May-1998, pp.527-534.

[15] D.Kirschen, G.Strbac, "Tracing active and reactive power between generators and loads using real and imaginary currents", IEEE Trans. on Power Syst., Vol.14, No.4, November-1999, pp.1312-1319.

[16] B.Khan, G.Agnihotri, G.Gupta, P.Rathore, "A power flow tracing based method for transmission usage, loss and reliability margin allocation", $2^{\text {nd }}$ AASRI Conference on Power and Energy Systems, AASRI Procedia, Vol.7, 2014, pp.94-100.

[17] M.De, S.K.Goswami, "Reactive power cost allocation by power tracing based method", Energy Conversion and Management, Vol.64, 2012, pp.43-51.

[18] A.Augugliaro, L.Dusonchet, S.Favuzza, M.G.Ippolito, E.R.Sanseverino, "A model for reactive power tracing by addition of fictitious nodal injections", Electric Power Systems Research, Vol.83, 2012, pp.196-202.

[19] W.Zhang, X.Guo, Y.Liu, D.Ni, L.Wang, Y.Jia, "A new power flow tracing method based on directed circuit", International Conference on Applied Physics and Industrial Engineering, Physics Procedia, Vol.24, 2012, pp. 50-55.

[20] K.Xie, J.Zhou, W.Li, "Analytical model and algorithm for tracing active power flow based on extended incidence matrix", Electric Power Systems Research, Vol.79, 2009, pp.399-405.

[21] S.Chellam, S.Kalyani, "Power flow tracing based transmission congestion pricing in deregulated power markets", Electrical Power and Energy Systems, Vol.83, 2016, pp.570-584

[22] S.Abdelkader, "Transmission loss allocation in a deregulated electrical energy market", Electric Power Systems Research, Vol.76, 2006, pp.962-967.

[23] G.Yesuratnam, D.Thukaram, "Congestion management in open access based on relative electrical distances using voltage stability criteria", Electric Power Systems Research, Vol.77, 2007, pp.1608-1618.

[24] K.Visakha, D.Thukaram, L.Jenkins, "Transmission charges of power contracts based on relative electrical distances in open access", Electric Power Systems Research, Vol.70, 2004, pp.153-161.

[25] T.Dhadbanjan, V.Chintamani, "Estimation of least loss power contracts in a deregulated environment", International Journal of Emerging Electric Power Systems, Vol.11, Issue-4, Article-1, 2010, pp.1-28.

[26] P.K.Hota, B.Mohanty, "Overload alleviation and determination of cost of rescheduling in an open access power system", International Journal of Power System Operation and Energy Management, Vol.1, Issue-3, 2011, pp.25-29.

[27] Hadi Saadat, "Power System Analysis", Tata McGraw-Hill, New Delhi, Edition 2002, Reprint, 2006.

\section{PROFILE OF AUTHORS}

\begin{tabular}{|l|l|}
\hline & $\begin{array}{l}\text { Prakash Kumar Hota was born in } 1963 \text { in India. He has graduated in Electrical and } \\
\text { Electronics Engineering from the National Institute of Technology (NIT), } \\
\text { Tiruchirapalli, India in 1985, received his M.Tech in Industrial Power Control \& } \\
\text { Electric Drives in } 1992 \text { from Sambalpur University, India and Ph.D in Electrical } \\
\text { Engineering from Jadavpur University, Kolkata, India in 1999. Currently, he is a } \\
\text { Professor of Electrical Engineering and Dean of Centre for Distance and Continuing } \\
\text { Education (CDCE) at Veer Surendra Sai University of Technology (VSSUT), Burla, } \\
\text { India. His research interests include Economic Emission Load Dispatch, Hydrothermal } \\
\text { Scheduling, Hybrid Power Generation Systems, Power Quality and Soft Computing } \\
\text { applications to different Power System Problems in Deregulated Environment. }\end{array}$ \\
\hline $\begin{array}{l}\text { Atulya Prasad Naik was born in Odisha, India in 1968. He has graduated in Electrical } \\
\text { Engineering from Institution of Engineers (India) in 1992 and received his M.Tech in } \\
\text { Power System from National Institute of Technology (NIT), Jamshedpur (Formerly, } \\
\text { RIT Jamshedpur) in 2002. He is a Ph.D research scholar at ITER, SOA University, } \\
\text { Bhubaneswar, India. Currently, he is an Assistant Professor of Electrical Engineering } \\
\text { and Head of the Computer Centre at Bhadrak Institute of Engineering and Technology, } \\
\text { Bhadrak under BPUT, Rourkela, India. His research interests include Loss Allocation } \\
\text { and Minimisation, Power factor Improvement, Voltage Control, Economic Operation } \\
\text { and Planning of Electrical Power Systems in the arena of Deregulated Power System. }\end{array}$ \\
\hline
\end{tabular}

